\title{
A Research on the Marketing Strategy of Artificial Intelligent Robot : Based on the Perspective of Customer Delivered Value Theory
}

\author{
Shujing Gao* \\ Tianjin Normal University Jingu College \\ No.393, Extension of Bin Shui West Road, Xi Qing District, Tianjin, China \\ gashujing@gmail.com \\ * The Corresponding Author
}

Keywords: Artificial intelligent robot; Customer delivered value; Total customer cost; Total customer value

\begin{abstract}
Since Philip Kotler's theory of customer delivered value has been put forward, it has been paid much attention by scholars and business scope. With the rapid development of artificial intelligent technology and the immature market, drawing on the content of the theory of customer delivered value in marketing is of great strategic significance to discuss the marketing strategy of artificial intelligent robot. The theoretical content of customer transfer value is expounded correctly at first in this paper. Then, from the perspective of customer delivered value theory, the market condition, total customer value, total customer cost and the influence of customer delivered value theory on the purchase decision of artificial intelligent is analyzed. It puts forward some rationalized marketing strategies finally to improve the total customer value and reduce the total customer cost, which has a certain reference significance for the marketing of artificial intelligent robot products.
\end{abstract}

\section{Customer Delivered Value Theory}

American management scientist Philip Kotler first put forward the theory of customer delivered value in the "marketing management" in 1990s. The theory holds that: customer delivered value refers to the difference between the total customer value and the total customer cost. The total customer value refers to a set of interests that customers expect to acquire for a product or service, including product value, service value, personnel value and image value. The total customer cost is the cost of goods or other forms consumed by a customer to purchase the value of a commodity, which is mainly composed of money cost, time cost, physical cost and mental cost[1]. The customer delivered value is expressed as a function of the form:

$\mathrm{CDV}=\mathrm{TCV}-\mathrm{TCC}$

The total customer value function:

$$
\mathrm{TCV}=\mathrm{F}(\mathrm{Pd}, \mathrm{s}, \mathrm{Ps}, \mathrm{I})
$$

Total customer cost function:

$$
\mathrm{TCC}=\mathrm{F} \quad(\mathrm{M}, \mathrm{T}, \mathrm{Py}, \mathrm{E})
$$

Therefore, the customer transfer value function can also be expressed as:

\section{$\mathrm{CDV}=\mathrm{F}(\mathrm{Pd}, \mathrm{s}, \mathrm{Ps}, \mathrm{I} ; \mathrm{M}, \mathrm{T}, \mathrm{Py}, \mathrm{E})$}

Philip Kotler believes that the customer is based on customer delivered value as a decisive factor in the purchase, because it determines the purchasing behavior and repetitive purchasing decisions, for customers, in the limited search capabilities, limited information and limited income and other factors, as a completely rational person. They seek to maximize the value of the transaction. Consumers purchase 
a product because they have customer delivered value, and customers always buy products from those who can provide more customer delivered value.

\section{Customer Delivered Value of Artificial Intelligent Robot}

Marketing Status of Artificial Intelligent Robots. The market of artificial intelligent robot products is in the period of rapid development and expected to be huge in the future. As an emerging high-tech product, artificial intelligent robot is in the initial stage of the product life cycle. The vast majority of user needs are still potential needs, and producers and operators need to excavate it. The target market of high-end artificial intelligent robot is high-end customers, who account for a small number of consumers. The low end artificial intelligent robots dominate the large ordinary consumer market. The market is still lack of understanding of artificial intelligent robot products, and can not form a large customer group. The sales channels of artificial intelligent robots are mainly concentrated in the network channels, and can not effectively expand sales channels, so that offline consumers lack enough user experience. There is a lack of a well-trained professional salesman in the market, and even the majority of the sales personnel of the artificial intelligent robot are transformed by the manufacturer. The product market of artificial intelligent robot is considerable in the future, but a large-scale marketing channel network has not been formed at present.

Analysis of Total Customer Value. The chief value of total customer value is product value, that is, the actual utility that products bring to consumers, usually the value produced by factors such as quality, function, specification and style of products, which is the core value of products. The total customer value also includes service value, personnel value and image value. These are added values of artificial intelligence robot products, which will affect consumers' feeling after purchase. Good after-sales service and all kinds of technical support provided by the company are part of the service value. Personnel value refers to the employees of the business idea, knowledge level, professional ability, work efficiency and quality, management style and the ability to produce value, a high-quality sales team and professional sales service can effectively improve the total customer value. The image value usually refers to the value produced by the overall image of the enterprise and its brand in the public.

Analysis of the Total Customer Cost. The most direct cost of the total customer cost is the money cost . The high-end artificial intelligent robot has a narrow audience because of its high price. Low end artificial intelligent robots are limited by various technical problems, resulting in limited functions that can be realized. Therefore, only a few consumers can accept their performance price ratio. Most of the consumers who can accept artificial intelligent products depend on the pursuit of fresh market pioneers and consumers who don't care about the cost of money. The market is still in the introduction period. Time cost, physical cost and mental cost are also part of the total customer cost. The time cost is the time that the customer must be in the waiting state to get the expected goods or services. Physical and mental cost refers to the consumption and expenditure of energy and spirit when the customer takes the purchase behavior[2]. Artificial intelligence robots are mainly online selling and lack of enough offline entity stores. When consumers want to buy Artificial intelligence robots, they usually have to spend time collecting information. This is a process of voluntary attention, which usually requires consumers to pay more mental cost and physical cost than involuntary attention .

Influence of the Customer Delivered Value on the Consumer's Purchase Decision. Based on the completely rational human hypothesis, customers always want to pay the lowest product cost while purchasing goods, and hope to get the greatest value at the same time, so that their needs can be maximally satisfied. Therefore, the decision of consumers' purchase behavior usually depends on consumers' judgement of customer delivered value, and the customer delivered value is positively correlated with the consumers' purchase behavior. In fact, because consumers' time, physical strength and energy are all limited, they often get incomplete information, that is, when information is not completely symmetrical, they have implemented purchase behavior. After the purchase behavior is produced, the consumer will produce a new user experience in the process of using the product, that is, the psychological perceived value. At this time, if the psychological perceived value is far greater than the expected value of customer delivered value, the consumer will have the pleasure of the post purchase 
satisfaction, and then produce a repeat purchase, or even become a loyal customer of the product or brand. If the post purchase value is less than expected, the consumer will have a pessimistic mentality. Then consumers will this empathy to the product, to gradually reduce the purchase of this product, and even complain about products and negative about it, It is very easy to cause the loss of market share of the product; If the two are equal, the consumer has no regrets for the purchase. This process is shown in Fig. 1.

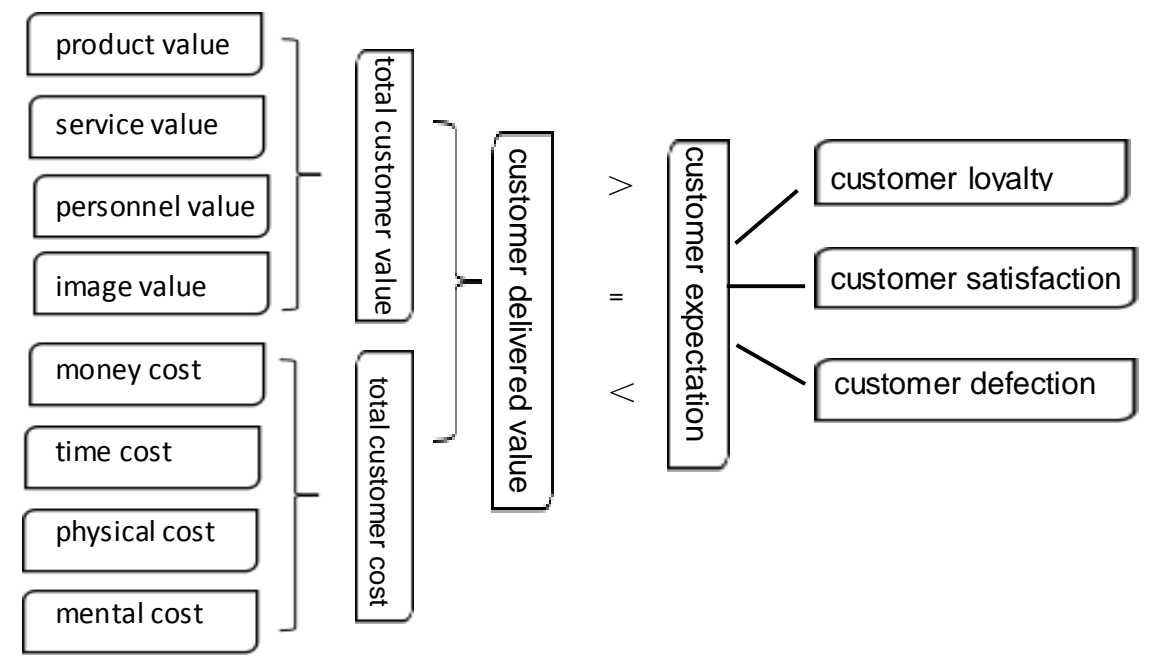

Figure 1. Customer delivered value frame

\section{Marketing Strategy}

Increase the Total Customer Value. The first is to improve the product value. The product value is also the first factor to be considered by the customer to choose the goods or services. The artificial intelligence robot is a high-tech product. In order to improve the core competitiveness of the product, it is necessary to carry on the technological innovation and scientific research innovation continuously. The concept of product includes three levels: core product (avail), form product (material, packaging, color) and additional products (installation, delivery, maintenance). Enterprises should strive to improve the quality of products in all aspects and achieve customer satisfaction. Second, improve the service value. Service is basically a kind of intangible activity, but it is often associated with tangible products. The improvement of service value will help to improve consumer's shopping experience and post purchase satisfaction, and form the consumer's favorable impression of the product. Enterprises can also establish customer relationship management system in the form of data mining, often do after-sales service, and improve service in time. There is also a need to improve the personnel value. The most precious resource in the enterprise is the human resource, which has the subjective initiative, especially the salesman. The salesman is the first window to show the customer and show the image of the enterprise. Enterprises need to develop a skilled salesman team who is skilled, responsive, enthusiastic and enterprising. They can use their marketing expertise to serve the sale of artificial intelligent robots. Finally, improve the image value. Reputation is better than popularity. It is an undisputable fact that in the field of marketing. Enterprises need to participate in public welfare activities regularly, so as to improve their reputation in consumers' minds. Enterprises should also actively undertake social responsibility to establish a positive corporate image and product image, which are beneficial to themselves, consumers and society.

Reduce the Total Customer Cost. The essential is to reduce the money cost. Product price is a very sensitive factor in the process of consumer decision making. Enterprises can reduce the production cost of unit products through large-scale production. While artificial intelligent robots are becoming more and more popular, the reduction of product prices has become a necessity. Secondly, reduce the time 
cost and physical cost. Products need to be close to the market. Market segmentation is conducted on the basis of identifying target customers, and then select the exactly promotion channels and media. Enterprises should actively approach target customers, make promote marketing and pull marketing to cooperate with each other, and provide convenience for consumers. Finally, reduce mental costs. Artificial intelligent robot is a high-tech product. Most consumers have no desire and don't need to spend the energy to understand the related knowledge in the field of artificial intelligence robot. Enterprises only need to let consumers know what benefits the AI robot can bring to consumers. Rather than wasting time and effort to sell many professional terms to consumers, we should actively promote experiential marketing and enable consumers to understand and accept artificial intelligent robots in a pleasant experience. When consumers are more and more fond of this pleasant experience, the sales of artificial intelligent robots are becoming unstoppable.

\section{Concluding Remarks}

The development prospect of artificial intelligent robot market is wide, but there is still a lack of mature marketing mode and marketing combination strategy. The theory of customer delivered value reveals that enterprise marketing should take customer demand as the guidance, and strive to improve consumers' purchase intention from two aspects: improving the total customer value and reducing the total customer cost. Customer's purchase decision affects the marketing strategy of an enterprise. The currency in the market is just like a vote, which determines the future development direction of an enterprise. Therefore, improving customer delivered value is the common pursuit of enterprises and consumers. Of course, the theory of customer delivered value only studies the marketing status of artificial intelligent robot from a specific perspective and puts forward corresponding strategies. Enterprises need to combine more marketing tools to analyze the integration plan while making marketing strategies.

\section{References}

[1] J.A.Wu, Y.K.Nie Marketing, (Higher Education Press,China 2014)

[2] H.J.Wang, L.H.Wei, Research about Customer Delivered Value Theory and Business Strategy , Management Observation, (2012) No.2, p.168-169.

[3] S.Q.Song, Research on Enterprise Competition Strategy based on Customer Value Oriented (Ph.D. Jilin finance and economics university, China 2014)

[4] S.Wangang,An Analysis of Network Marketing Strategy based on the Customer Delivered Value Theory, Time Finance, (2017) No.18, p.196-197.

[5] Y.S.Wangang,An Analysis of the Application and Development Prospect of Artificial Intelligent Robot, Modern Information Science and Technology, vol.1(2017) No.2

[6] W.M.Fei, A Study on the Promotion of Tourists' Satisfaction in the Internet Background -- Based on the Customer Delivered Value Theory, Money Economy,(2017) No.7, p.150-152.

[7] J. L.Wang,X.L.Wang,Customer Cognitive Value Model under the Environment of Network Marketing, Journal of Harbin University of Commerce (Social Science), (2011) No.6, p.15-20.

[8] N.N.Meng, An Analysis of Free Marketing Strategy based on the Customer Delivered Value Theory, Market Modernization, (2016) No.25, p.91-92.

[9] L.Q.Gu,X.X.Lai, An Analysis of the Way to Improve the Customer's Delivered Value Theory from the Perspective of Economics, Value Engineering,(2013) No.25, p.149-150.

[10] Y.N.Sun, A Brief Discussion on the Development Trend of Artificial Intelligence Robot, Electronic Test, (2016) No.23, p.24-25. 